\title{
Innovation in University's Physical Education Teaching Methods
}

\author{
Viet-Chau Thi To* \\ Trade Union University, Vietnam.
}

*Corresponding Author: Viet-Chau Thi To, Trade Union University, Vietnam.

\begin{abstract}
In the progress of teaching physical education in university, outside of focusing on the teaching contents, the teachers also have to focus on how to conduct, how the students can acquire and develop physical knowledge, skills.
\end{abstract}

Keywords: teaching methods, physical education, university.

\section{INTRODUCTION}

By analyzing physical education teaching methods, classifying the means of teaching physical education, the author has clarified the current university physical education learning problems in Vietnam.

\section{RESULTS}

Based on the actualization of the teaching activities, teaching methods structure, we can see that: The systematic structure of the teaching methods includes elements like purpose, action, means, subject actions and mechanisms to reach the goal.

The use of teaching media comes from the purposes of the teachers and students have to cooperate with the teachers' leading role when guiding the students using the media.

- $\quad$ When applying a particular teaching method, it is necessary to:

$+\quad$ Choose the teaching method that corresponds to the operational measures of the teachers and students.

$+\quad$ Identify the position of each method and technique using each teaching medium suitable to every unit of knowledge in the class.

The relationship between teaching means and method is also reflected in developing the teaching methods and contents. In contrast, the content must consider the medium to list the necessary means and visualize the specific contribution of the means to the learning progress. Thus, the content, teaching method change according to social needs and require the teaching to change.

* Classification of teaching means and the role of physical education teaching means.

To innovate the means of teaching, physical education needs to determine the medium's position and role in teaching progress.

a) Classify The Teaching Medium:

According to the use of teaching media, the classification is suitable for the teaching media system used in universities today. Therefore, the teaching means can be divided into two groups.

- $\quad$ The media used directly for teaching includes two subgroups:

$+\quad$ Traditional means are those that have been used for a long time and are still being used today in some places.

$+\quad$ The means by sound and visual were formed by the development of science and technology, especially the development of information technology.

- The means used to prepare and control the classroom includes supporting means (Writing boards, fixed and portable shelves, classroom lighting equipment,...) and recording means.

In reality, when it comes to using teaching media in universities today, people often pay attention to technical means and equipment to teach directly. As a result, teaching aids are usually classified as teaching infrastructure. 
b) Classify the physical education teaching medium:

* Based on classifying the teaching media, the physical education direct teaching means are classified into traditional and technical means. According to this classification, the traditional means (except for some modern pieces of equipment and means) include most of the media used so far: practice rooms and grounds, pictures, timers, whistles, and other tools to train skills, techniques, and physical strengths. On the other hand, the technical means and equipment are modern (projectors, video players, televisions, physical training, and analyzing software, recorders, computers, and related software) [1].

Thus, the physical education teaching media system teaches directly and includes two large groups: traditional and modern means.

* Group 1: Traditional means of teaching. This group includes many subgroups:

- $\quad$ The means that indirectly reflect the subjects (Textbooks, thematic books, reference books,...).

Visual aids to recreate the objects, physical phenomena as their characteristics in nature.

- $\quad$ Measuring instruments related to physical activities (stopwatch; tape measure; weight scale; vital capacity blower,...).

The mediums reflect the physical education and symbolic objects (models).

* Group 2: Modern means of teaching: projectors, electronic computers, assessing fitness software and pieces of equipment, physical education videos, dynamic models, modern research pieces of equipment.

This classification facilitates selecting the unique advantages of different physical education teaching means according to the lecture content to use the most effective methods.

c) The role of media groups in teaching physical education

* Traditional mediums in teaching physical education

- In the above physical education teaching system, the advantage of traditional means is to provide and convey the essential information to the students under the available content of the program. The conventional means are easy to use and require few technical requirements such as power supply, Internet, department rooms, skills, which is very relevant to rural and remote areas in Vietnam. With the advantages mentioned above, the innovation of teaching media in the direction of positive cognitive activities of learners depends on the lesson must rely on traditional teaching means. These teaching media are also mainly suitable for class-based teaching. Therefore, the conventional teaching means in physical education is dispensable.

However, in the current trend of teaching innovation today, the use of traditional teaching means still has the following limitations:

$+\quad$ The traditional teaching means cannot thoroughly analyze the physical education knowledge, such as:

* These teaching media can only be expressed in the static form of physical education. Therefore, the use of these media will hardly reflect the physical education processes with its movement and development.

* It is also difficult for traditional teaching mediums to describe a physical activity, a field of physical training, and sports activities with their complete characteristics.

* To describe a sport technique or the problems about the amount of the movement, the principle of the activities synthetically, it is challenging to use only the traditional teaching mediums. Until now, many traditional mediums such as pictures, models, stopwatches are mainly used for classroom teaching. The sections for self-learning and other methods are still small and contain unattractive content. It can be seen that: to express the properties of many physical education objects; it is difficult for traditional mediums to express vividly and intuitively.

* Modern mediums in teaching physical education

- The most critical means in teaching physical education today are audio-visual means. Their common feature can form the basis of human perception by directly impacting the senses: hearing, sight, or both hearing and sight. Among the mediums of hearing, sight, video, the Internet, pieces of equipment and software to support assessing the exercise level, multimedia communication,..., has the most crucial role determined by many researchers such as the ability to provide, store, and export 
information, the ability to teach individually, to learn for life,... For teaching physical education in universities, modern audio-visual means also has a significant meaning.

$+\quad$ Information sources through the modern audio-visual means include curriculum-based information of most traditional teaching means, including rich, visual sources of information reflect the physical education subjects realistically: pictures, illustrations, photos, drawings, videos, software assessing the body's biological ability in the exercise process. For example, the Smart Speed system help analyzes segment speed, flexibility, and motor reflex, strength, and speed; the equipment and software Lactate Scout Pack assesses the amount of exercise and aerobic fitness level. Furthermore, the software helps analyze the technical movement of sports, helps the user to realize the limitations, mistakes in the performing process...

$+\quad$ At a higher level, using these audio-visual means in physical education can build virtual experiments about the exercise process in an environment that hardly any teaching equipment can do (Analyzing the situations that happen in sports competitions,...). One cannot rely on the physical education objects on the training ground for students to practice, much less create them in a university's lab. Observations and practice with these experiments will bring changes, which are:

* The students will understand the nature of sports activities instead of recognizing them as they are today.

* Through these hands-on experiments, the students will have a fuller sense of their own and the community activities in the environment they live in.

* Through collecting and processing the information from these mediums, the students not only form skills and techniques but also acquire the skills in using modern audio-visual mediums.

- $\quad$ By exploiting the advantages of many different art forms, techniques,... in making the videos, computer-based learning programs, many physical education phenomena can be reflected in the form of movement, abstract, different perspective that the conventional methods cannot reflect on. This also brings strong perceptive power, improving the cognitive and training efficiency for students in physical education.

$+\quad$ Furthermore, in physical education, the modern audio-visual means also have many advantages: To provide a large amount of regularly updated information. This source of information facilitates a timely reflection of the achievements of the science behind sport and physical education and practical problems posed. Therefore, it is an indispensable requirement in education. limitations.

Besides the primary advantages, using these means in universities today still has many

$+\quad$ Physical education videos and software are rare in Vietnam. Foreign software is to use because of the language barrier or unsuitable program.

$+\quad$ Abundant sources of information and vivid images and sounds are essential advantages of modern audio-visual media. However, if these sources of information are selected incorrectly, then making them into videos or software will not meet the physical education's requirement.

$+\quad$ Up to now, the method of using these means in universities has had specific orientations.

$+\quad$ Synchronously equipping a modern audio-visual equipment system requires a large investment in materials, technical, and appropriate human resource training.

* Trends of innovation in physical education's means in universities

It can be seen that the innovation of teaching methods requires changes in teaching means. The use of teaching means in universities today is based on promoting the positive aspects of traditional means combined with the outstanding advantages of traditional and information technology. This is the direction of innovating the teaching means. Thus, it is necessary to supplement and select modern means for teaching at universities in addition to the available means.

The issue of innovation in teaching has been researched and studied by many authors. According to [2], [3], in the current period, many teaching means must improve to suit the objectives, contents, teaching methods, must be researched and used by both lecturers and students. They also must ensure to enhance practical and experimental skills for the students. They must also be versatile, safe, inexpensive, and synchronously implemented on different subjects and grade levels and mix tradition and modernity. Many other authors are interested in renovating current teaching means 
associated with applying information and communication technology [4], [5]. Technology is creating vital developments in every aspect of social life. The renewal of objectives, contents, and teaching means in universities today requires strengthening universities' physical and technical infrastructure. Technical means, first of all, audio-visual means of information and communication technology, holds an important position. The means such as personal computers, digital videos, projectors, televisions, software, ,.. have an essential part in innovating teaching means [3] [5].

- $\quad$ Teaching physical education in universities today must pay proper attention to the use of these media. In the research on physical education science, many modern means and pieces of equipment have been used, such as digital cameras, equipment to study metabolism and physiological functions, some related software.

However, in teaching physical education in universities, the means innovation is minimal, reducing the ability to innovate the teaching methods and hard to improve the quality of physical education.

\section{CONCLUSION}

The rational use of audio-visual means in teaching physical education will help the students to acquire well a rich, visual, and attractive source of knowledge and create an interactive relationship between the students - means - the primary role of the lecturer. This use is a favorable condition for the teacher to organize the activities in the direction of positive cognitive activities of the students. In renewing methods and improving the quality of physical education, each group of teaching means has an important role. If the use of modern audio-visual means has a significant meaning to enhancing the senses, providing a rich source of information to facilitate students' independent and active learning,... Then the use of traditional means such as pictures, models, and diagrams has a great significance in developing imagination, training skills, techniques, and developing physical education training for students.

\section{REFERENCES}

[1] Nguyen Trong Phuc (2010), Means, equipment and techniques in teaching, Vietnam National University, Hanoi Publishing House.

[2] Pham Minh Hac (2000), "Knowledge economy and education - training and developing people", Educational Research No.9, p. 4, 5 \& 6.

[3] Quach Tuan Ngoc (2009), "Innovating teaching methods by information technology - Trend of the times", University and Professional Education No. 7, p. 24-26.

[4] Tran Doan Quoi (2000), Ministerial-level scientific research project on educational audiovisual media, Summary report on research project, Vietnam Institute of Educational Sciences, Hanoi.

[5] VuThe Quan (1991), "Developing listening-visual techniques a way to modernize teaching means and methods", Educational Research No.2, p. 12-13.

\section{AUTHOR'S BIOGRAPHY}

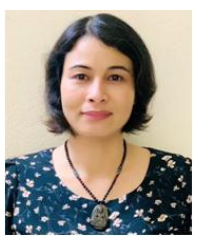

Viet-Chau Thi To (MSc), is head of Department of Physical Education at Trade Union University, Vietnam. She is in charge of physical education and sport activities for undergraduate students, and has been managing all sport examination and competitions for the university for more than 20 years.

Citation: Viet-Chau Thi To. "Innovation in University's Physical Education Teaching Methods" International Journal of Humanities Social Sciences and Education (IJHSSE), vol 8, no. 9, 2021, pp. 82-85. doi: https://doi.org/10.20431/2349-0381.0809008.

Copyright: (C) 2021 Authors. This is an open-access article distributed under the terms of the Creative Commons Attribution License, which permits unrestricted use, distribution, and reproduction in any medium, provided the original author and source are credited. 